\section{Empfindsames Schmerzgedächtnis Wenn Wörter dem Gehirn wehtun}

\begin{abstract}
> Das Schmerzgedächtnis reagiert auf schmerzassoziierte Wörter genauso wie auf tatsächliche Schmerzen. Das haben Wissenschaftler der Universität Jena jetzt herausgefunden. In einer funktionellen Magnetresonanztomographie (fMRT) zeigten sich die schmerzverarbeitenden Hirnareale aktiv, wenn die Probanden Wörter wie „quälend“, „zermürbend“ oder „plagend“ zu hören bekamen. Für andere negativ belegte Wörter wie „widerlich“ oder „eklig“ ließ sich dieser Effekt
\end{abstract}

nicht nachweisen. Das Gleiche galt für neutrale und positiv besetzte Wörter.

Auf die Therapie chronischer Schmerzen wirft diese Erkenntnis ein ganz neues Licht. Spricht der Patient mit seinem Arzt über empfundene Schmerzen, könnte das sein Leiden verstärken. Weitere Studien sollen diese Theorie überprüfen. Bis dahin sei geraten, auf die Zähne zu beißen und nicht zu häufig über Schmerzen zu reden.

(ch)

Pressemitteilung FSU Jena 26.03.2010
Dr. Sonja

Kempinski Chefredakteurin

\section{„Gehabte Schmerzen ...}

... die hab ich gern" - wohl gesagt, Wilhelm Busch. Doch wie schwierig ist es für Schmerzpatienten, in dieses Stadium der wohlmeinenden Rückschau zu gelangen! Zwar gibt es eine Vielzahl therapeutischer Möglichkeiten, aber vom Hausarzt bis zum Schmerzspezialisten kennt jeder Kollege Patienten, an denen man sich in puncto Schmerzbekämpfung fast die Zähne ausbeißt. Wie schön wäre es, könnte man einfach auf eine "Löschen"-Taste drücken und schon sind die Schmerzen weg! Doch auch wenn es diesen Knopf nicht gibt, so sind die Experten doch mehr und mehr dem Schmerzgedächtnis auf der Spur, und das sogar mit einigem Erfolg, wie auf dem Deutschen Schmerz- und Palliativtag berichtet wurde. Dort gab es auch Spannendes zur Hyperalgesie, einer paradoxen Nebenwirkung der Opioidtherapie, zu hören. Warum Opiate überhaupt zu vermehrtem Schmerz führen können und wie dieser Wirkung beizukommen ist, erfahren Sie neben interessanten Erkenntnissen zu Muskelkater und Grundrechten in unserem Schwerpunkt "Schmerz".

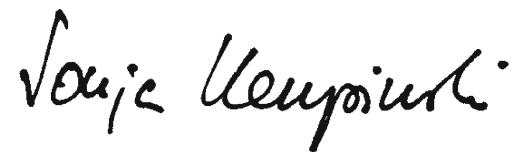

\section{Lumbalgie schwindet von selbst}

> Eine chronische Lumbalgie hat gute Heilungschancen. In einer australischen Studie mit 400 Patienten gaben 35\% der Teilnehmer nach neun Monaten an, dass sie nicht mehr unter Rückenschmerzen litten; nach zwölf Monaten waren es sogar schon $41 \%$. Dabei wurden spezifische Ursachen wie Krebs, Infektionen, Frakturen oder Arthritis nicht berücksichtigt. Patienten mit neu einsetzenden chronischen Rückenschmerzen kann man also Hoffnung auf Heilung machen! (cd) Menezes L et al, BMJ 2009, 339:b3829
Psyche an Platz zwei der Dauerschmerz-Verursacher

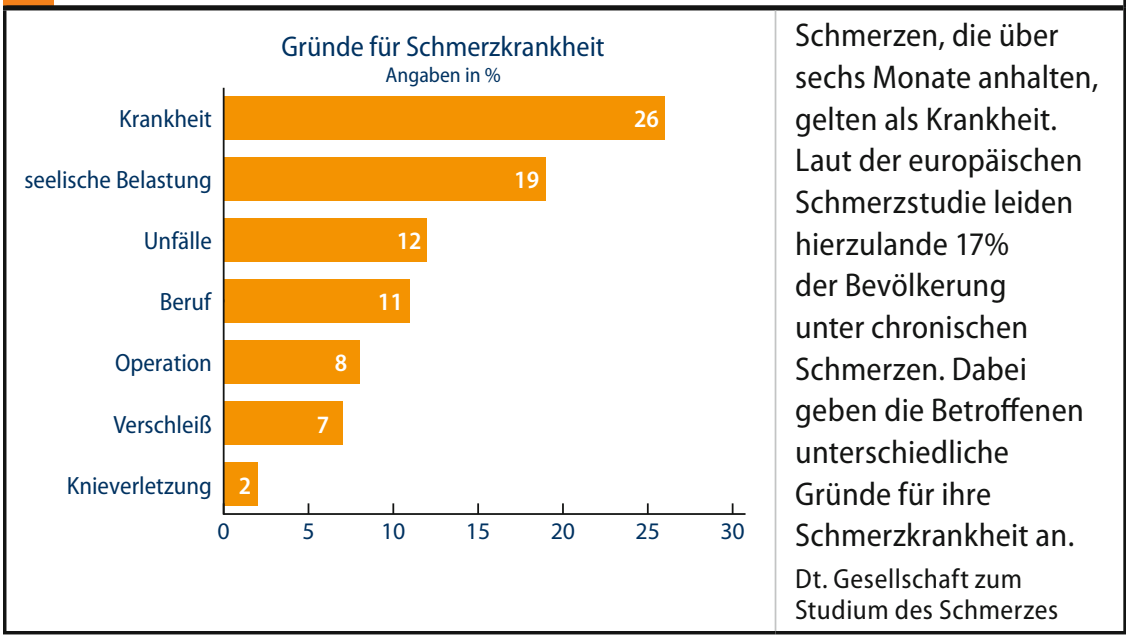

